\title{
Piezo harvesting of bone grafts from the anterior iliac crest: A technical note
}

\begin{tabular}{l} 
Access this article online \\
Website: \\
www.amsjournal.com \\
\hline DOI: \\
10.4103/2231-0746.186131 \\
\hline Quick Response Code: \\
\end{tabular}

\author{
Leena P. Ylikontiola', Ville Lehtonen', George K. Sándor ${ }^{1,2}$ \\ ${ }^{1}$ Department of Oral and Maxillofacial Surgery, Medical Research Center, Oulu University Hospital, \\ Institute of Dentistry, University of Oulu, Oulu, ${ }^{2 B i o M e d i T e c h, ~ I n s t i t u t e ~ o f ~ B i o s c i e n c e ~ a n d ~ T e c h n o l o g y, ~}$ \\ University of Tampere, Tampere, Finland \\ Address for correspondence: \\ Dr. Leena P. Ylikontiola, University of Oulu, Aapistie 5A, Office No: 2126B, 90014 Oulu, Finland. \\ E-mail: leena.ylikontiola@oulu.fi
}

\section{ABSTRACT}

Background: Autogenous bone graft harvesting from the iliac crest is associated with donor site morbidity. The aim of this report is to describe the use of piezosurgery as an attempt at morbidity reduction. Materials and Methods: A piezosurgical handpiece and its selection of tips can easily be accommodated in an iliac crest wound to osteotomize and allow the harvest and delivery of autogenous bone grafts. Results: Corticocancellous blocks or cancellous strips of autogenous bone can be readily harvested using a piezosurgical technique at the anterior iliac crest. Conclusion: Piezosurgery avoids some of the traumatic aspects of harvesting bone associated with the use of conventional rotary instruments or saws.

Keywords: Bone graft, iliac crest, piezosurgery

\section{INTRODUCTION}

Autogenous bone remains the gold standard grafting material to treat bone defects in the craniomaxillofacial skeleton. ${ }^{[1,2]}$ Harvesting autogenous bone results in donor site morbidity. ${ }^{[3,4]}$ Numerous donor sites have been described. ${ }^{[3]}$ Many approaches have been tried. ${ }^{[5]}$ While new instrumentation has been developed, ${ }^{[6,7]}$ donor site morbidity still remains a challenge.

One approach is to eliminate all conventional heat-producing instrumentations known to injure the bone. This includes the use of rotary drills, reciprocating, or oscillating saws. The development of piezosurgical instrumentation has radically changed many surgical approaches in the craniomaxillofacial skeleton. ${ }^{[8,9]}$ While time intensive at first, piezosurgery is less traumatic to bone and neighboring vital structures than conventional instrumentation. ${ }^{[8,10]}$ This technical note aims to describe the application of piezosurgery for the harvesting of autogenous bone graft material at the anterior iliac crest site.

\section{MATERIALS AND METHODS}

The medical approach to the anterior iliac crest is well known in the literature. ${ }^{[3,4]}$ Once the anterior iliac crest is exposed, the medial wall of the iliac wing is made accessible by retraction. A piezo handpiece and surgical unit (Synthes, Oberdorf, Switzerland) and a selection of serrated tips are used [Figure 1]. The tips are available in long and short lengths. Tip configurations with a straight profile and with the right or left bends are also available. The tips are interchangeable so that the most advantageous tip can be selected to make the vertical and horizontal osteotomies through the medial cortex of the iliac bone [Figures 2 and 3].

The piezosurgical tip easily allows the creation of a straight line osteotomy through the medial cortex, up to the level of the lateral cortex but not through it [Figure 3]. A trap door

This is an open access article distributed under the terms of the Creative Commons Attribution-NonCommercial-ShareAlike 3.0 License, which allows others to remix, tweak, and build upon the work non-commercially, as long as the author is credited and the new creations are licensed under the identical terms.

For reprints contact: reprints@medknow.com

Cite this article as: Ylikontiola LP, Lehtonen V, Sándor GK. Piezo harvesting of bone grafts from the anterior iliac crest: A technical note. Ann Maxillofac Surg 2016;6:94-6. 
at the anterior iliac crest allows access to the superior most aspect of the iliac crest which is moved laterally exposing the underlying cancellous bone. The depths of the piezo osteotomies cuts can be visualized. A chisel can then be used in a gentle prying fashion to deliver the corticocancellous block or cancellous strips. Wound closure is unaltered by the piezosurgery [Figure 4].

\section{RESULTS}

The piezosurgical handpiece was easily fitted into the wound at the anterior iliac crest and allowed sufficient access, so the two parallel vertical osteotomies and the horizontal connecting osteotomy could be completed. The piezosurgical tips were able to reach the farthest part of the wounds without difficulty. Copious irrigation of the piezosurgical handpiece provided good visualization of the osteotomy site throughout the harvesting procedure while properly suctioning the wound. Bone grafts consisting of large corticocancellous blocks and cancellous strips were harvested without complication. There were no problems with postoperative ambulation.

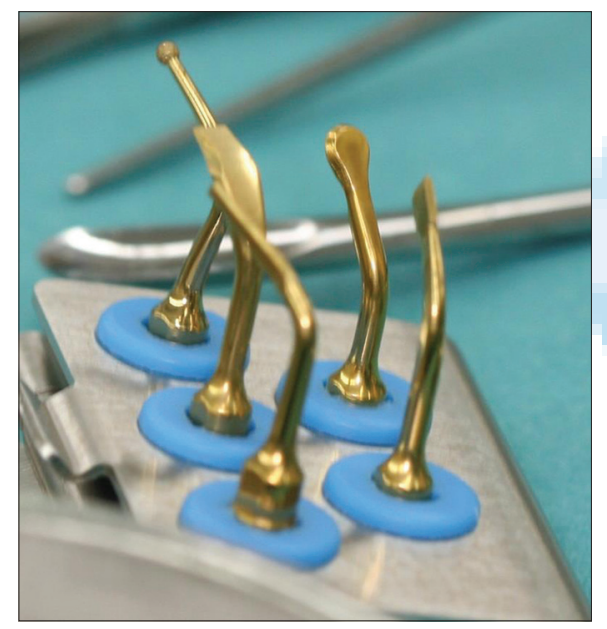

Figure 1: Selection of piezosurgical tips

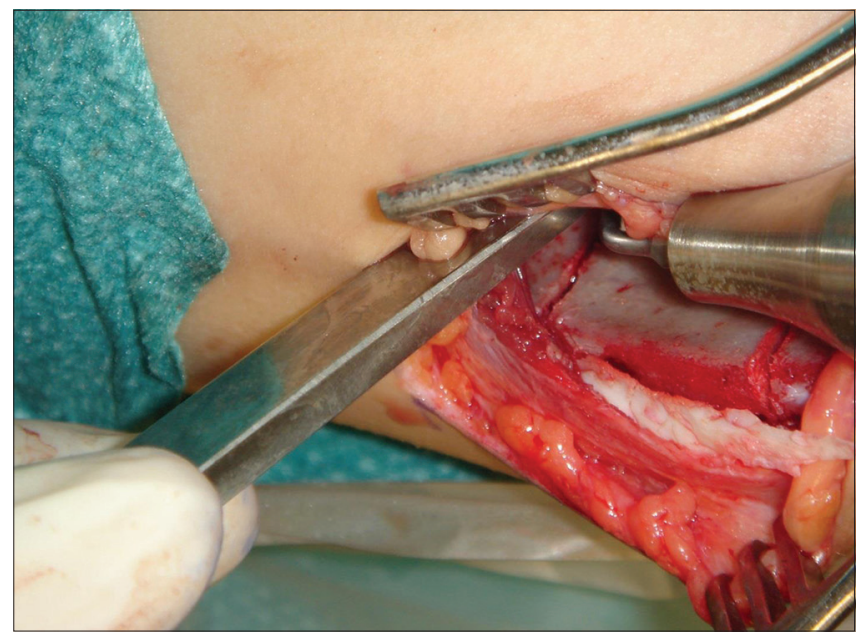

Figure 3: Photograph illustrating the two parallel cuts completed through the medial cortex

\section{DISCUSSION}

The application of piezosurgery to the anterior iliac crest for bone harvesting makes for a safer technique. Conventional instrumentation relies on saws, drills, or chisels ${ }^{[4]}$ which are all instruments with sharp edges with the potential to damage vital structures medial to the surgical site. All piezosurgical instrumentation is based on ultrasound bone cutting so that the instrument edges are blunt or rounded. This makes untoward trauma to nearby vital structures even less likely. Damage to the bone at the cellular level is also diminished as heat production is minimized. ${ }^{[8,10]}$ In the future, the authors plan to document postoperative pain scores and the time to ambulation, in order to compare piezosurgical harvesting of bone at the anterior iliac crest with conventional instrumentation. ${ }^{[4,6]}$

\section{CONCLUSION}

Piezosurgical harvesting of bone at the anterior iliac crest avoids the trauma and heat generation associated with conventional instrumentation. Long-term follow-up and comparison of risk-benefit analysis would yield further clues.

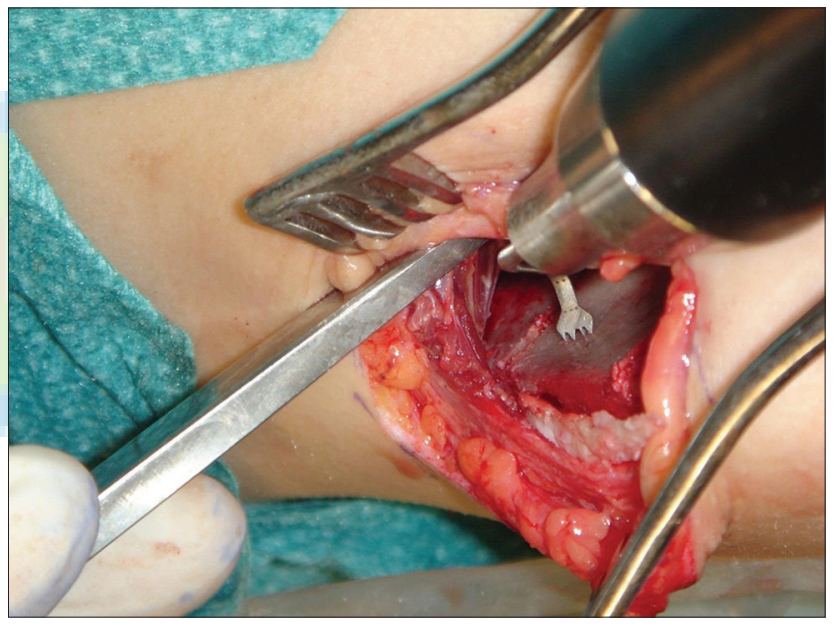

Figure 2: Photograph showing piezosurgical tip making the vertical osteotomy through the medial cortex of the iliac bone

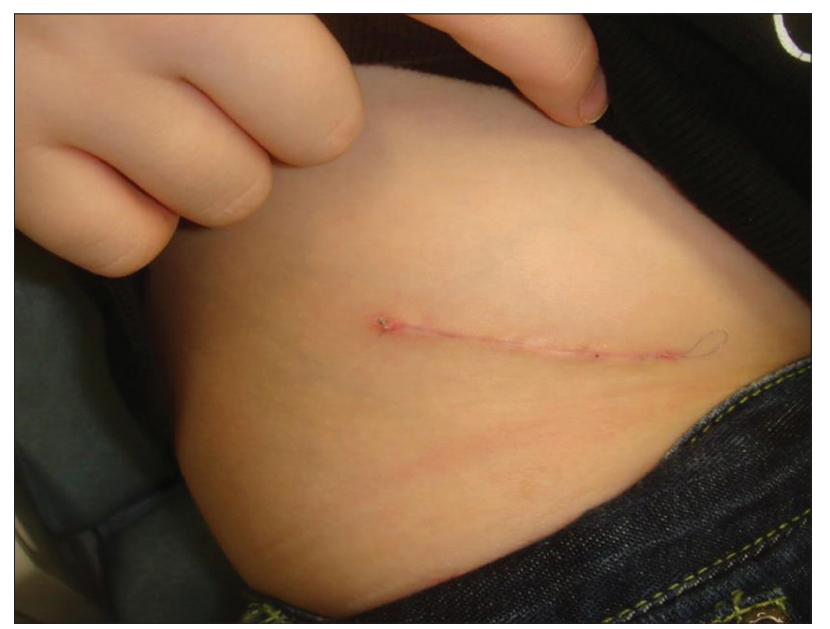

Figure 4: Appearance of healing iliac crest bone graft harvest wound 2 weeks after harvesting procedure 


\section{Acknowledgments}

The authors wish to acknowledge the University of Oulu for its support of this project.

\section{Financial support and sponsorship}

The authors wish to thank the EVO/VTR fund of the Oulu University Hospital for its generous financial support of this project.

\section{Conflicts of interest}

There are no conflicts of interest.

\section{REFERENCES}

1. Sándor GK. Tissue engineering of bone: Clinical observations with adipose-derived stem cells, resorbable scaffolds, and growth factors. Ann Maxillofac Surg 2012;2:8-11.

2. Harrell DB, Caradonna E, Mazzucco L, Gudenus R, Amann B, Prochazka V, et al. Non-hematopoietic essential functions of bone marrow cells: A review of scientific and clinical literature and rationale for treating bone defects. Orthop Rev (Pavia) 2015;7:5691.

3. Kainulainen VT, Sàndor GK, Caminiti MF, Clokie CM, Oikarinen KS. Extraoral bone harvesting sites for oral and maxillofacial surgery. Suom
Hammaslääkärilehti (Finn Dent J) 2002;10:570-6.

4. Sàndor GK, Nish IA, Carmichael RP. Comparison of conventional surgery with motorized trephine in bone harvest from the anterior iliac crest. Oral Surg Oral Med Oral Pathol Oral Radiol Endod 2003;95:150-5

5. Caminiti MF, Sándor GK, Carmichael RP. Quantification of bone harvested from the iliac crest using a power-driven trephine. J Oral Maxillofac Surg 1999;57:801-5.

6. Sàndor GK, Rittenberg BN, Clokie CM, Caminiti MF. Clinical success in harvesting autogenous bone using a minimally invasive trephine. J Oral Maxillofac Surg 2003;61:164-8.

7. Freilich MM, Sándor GK. Ambulatory in-office anterior iliac crest bone harvesting. Oral Surg Oral Med Oral Pathol Oral Radiol Endod 2006;101:291-8.

8. Spinelli G, Mannelli G, Zhang YX, Lazzeri D, Spacca B, Genitori L, et al. Complex craniofacial advancement in paediatric patients: Piezoelectric and traditional technique evaluation. J Craniomaxillofac Surg 2015;43:1422-7.

9. Echchadi ME, Benchikh B, Bellamine M, Kim SH. Corticotomy-assisted rapid maxillary expansion: A novel approach with a 3-year follow-up. Am J Orthod Dentofacial Orthop 2015;148:138-53.

10. Ma L, Mattheos N, Sun Y, Liu XL, Yip Chui Y, Lang NP. Wound healing of osteotomy defects prepared with piezo or conventional surgical instruments: A pilot study in rabbits. J Investig Clin Dent 2015;6:211-20. 